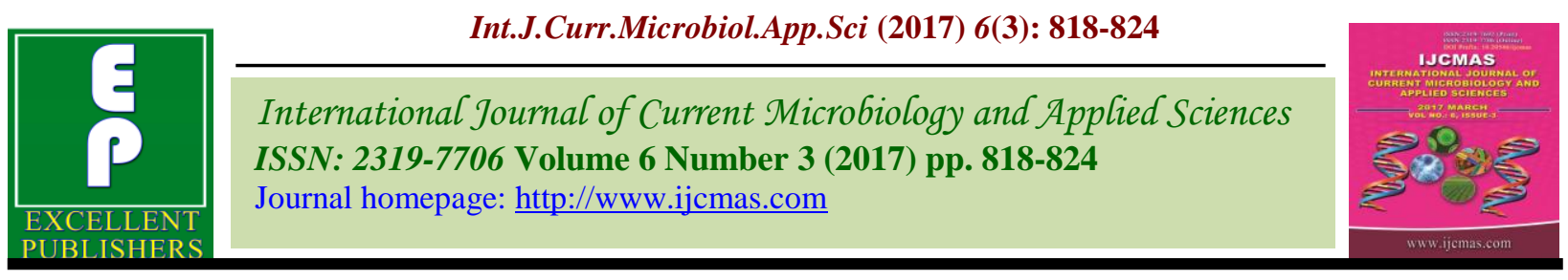

Original Research Article

https://doi.org/10.20546/ijcmas.2017.603.096

\title{
Diagnosis of Chikungunya by a Rapid Immunochromatographic Method in a Tertiary Care Setting
}

\author{
Swapna Kurup Rajgopal* \\ Department of Microbiology, Karpagam Faculty of Medical Sciences and Research, \\ Coimbatore, Tamilnadu, India \\ *Corresponding author
}

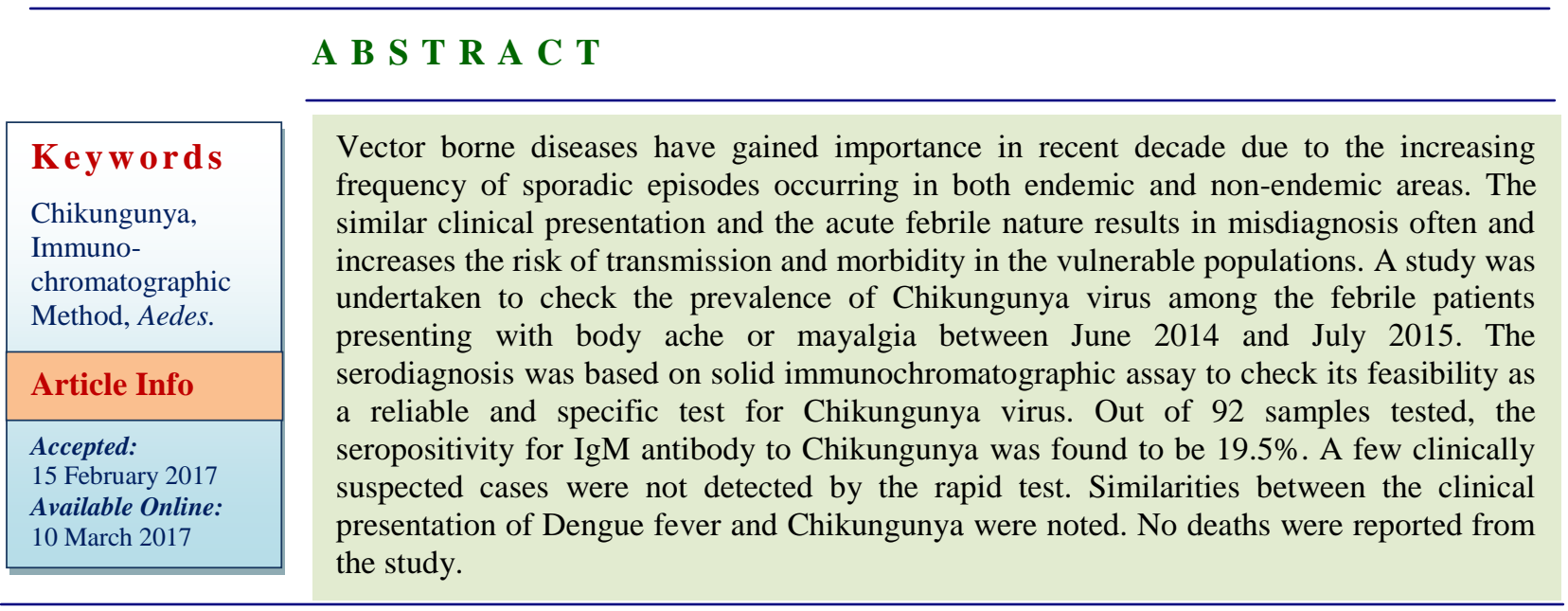

\section{Introduction}

Arboviral diseases are increasingly becoming prevalent in areas where the government initiatives have failed to control these vectorborne diseases. Mosquitoes over the decades have become adapted to the various means of eradicating them and pose a great public threat in tropical regions. The temporal changes in the seasons, breaking down of social hygiene, overpopulation, migrating population represented by job seekers, tourist and the medical tourists have made the management of vector-borne diseases beyond an individual government's control.

Aedes mosquito is one of the most adapted of the mosquito vectors (WHO, 2009). Being anthropophilic, its biting and nesting habits enable it to survive efficiently in the cities and villages. They bite during the day and night (Blacksell et al., 2011).

Two common species of Aedes, A. aegypti (Stegomyia aegypti) and A. albopictus (Stegomyia albopicta) are responsible for transmitting Chikungunya, Dengue, Sindbis Semliki, forest and eastern equine encephalitis. The mode of transmission is through the bite of infected female Aedes mosquito. The seasonality of these diseases and the common vector increases the risk of co-infection of Dengue with Chikungunya in India. In a study, Aedes albopictus, was reported as the predominant species for transmitting the infection in the city suburbs, 
easily breeding in flower pots and shrubbery while Aedes aegypti was more frequently associated in the city. Both Aedes aegypti and Aedes albopictus are known to be resistant to dichlorodiphenyl-trichloroethane (DDT; 4\%) which is commonly used by Indian Municipalities to control the mosquitoes in the cities, but are susceptible to 5\% malathion (Dev et al., 2014).

Chikungunya virus is an enveloped, singlestranded RNA virus of the alphavirus genus (family Togaviridae). Prior to 2013, the chikungunya viruses were limited to the east Asia, south east Asia, the Indian subcontinent, Africa and few parts of Europe. Since then, the disease has been noted in many countries causing outbreaks (CDC, 2015).

Most patients develop sudden onset of symptoms beginning within 3-7 days of the bite, developing fever and peripheral joint pains. Other symptoms such as headache, body-ache, muscle cramps or rash may be confused with other encephalitic presentations. The disease may sometimes be misdiagnosed as Dengue or Malaria in endemic areas (Murray et al., 2012). The morbidity due to the cramps and joint pains is high which may persist in many patients for few weeks after the treatment is started. The management of the infection is symptomatic including antipyretic drugs, chloroquine and ribavirin. Interferon-alpha, in some studies, have been stated as useful (Briolant et al., 2004).

The seasonality of these diseases and the common vector increases the risk of coinfection of Dengue with Chikungunya in India. The similar clinical presentation and the complications that complicate the management which is usually supportive treatment makes it essential to include the laboratory diagnosis of Chikungunya in all patients who is suspected of pyrexia of unknown origin.

\section{Materials and Methods}

The study was conducted in a 100 bedded tertiary hospital between June 2014 and July 2015 in the Mysuru district. Serum samples collected from 92 patients who were suspected of Pyrexia of unknown origin (PUO) were tested for IgM antibodies against Chikungunya. Informed consent was taken from the patients and approval from the Institutional Ethics committee obtained for the study. All patients who presented with acute febrile illness $<5$ days with joint pains or myalgia or severe body ache were included in the study. Other tests were done as routine requested by clinicians to rule out Dengue, Leptospirosis and Malaria by peripheral smear Weil Felix test and Widal test as part of fever panel.

IgM antibody to Chikungunya virus was detected using SD BIOLINE Chikungunya $\operatorname{IgM}$ test. This is rapid qualitative test based on immunochromatographic assay.The card has two pre-coated lines, "T" (Chikungunya recombinant structural protein), and "C" (Goat anti-mouse IgG) on the surface of the device. The monoclonal anti-human $\operatorname{IgM}$ is conjugated with colloidal gold. The gold colloid will react specially with IgM antibodies to Chikungunya in human serum, plasma or whole blood. Control line should always appear if the test procedure is performed correctly. Positive result is seen as appearance of " $\mathrm{T}$ " line turning purple after 10 mins. A serum sample of 50microliters is added to the card followed by 1 drop of the assay diluent into sample well. The results were correlated with clinical records retrospectively.

A patient with a suspicion of Chikungunya infection was termed as probable case while other patients whose clinical and laboratory criteria satisfied the defined criteria were termed confirmed cases (Directorate of 
NVBDCP, 2016). For laboratory confirmation a single test of positive serum sample for Anti-Chikungunya IgM was used to confirm the infection.

\section{Results and Discussion}

During the 13 month period, 92 samples were analysed for the presence of the virus specific IgM antibodies. The female to male ratio was noted as 1:1.1 and the age ranged from 19 to 78 years (Table 1 )

Of the 92 suspected cases for Chikungunya, 18 samples (19.56\%) gave positive results for IgM antibodies to Chikungunya virus, Dengue $\operatorname{IgM}(15)$, Rheumatoid arthritis (3) and septic arthritis (4), 3 peripheral smear positive for Plasmodium Vivax,1 adult Measles, 2 cases UTI, Atypical pneumonia (1) and H1N1(1). 44 samples were negative for tests in the Fever panel including Widal and blood culture $(47.8 \%)$.

The characteristics of the fever in the 18 confirmed cases was of sudden abrupt onset with temperature ranging from $101-104^{*} \mathrm{C}$, rarely with chills ( 2 cases) and intermittent in 4 cases. The rash was of either macular erythema or petechial type described over trunk or abdomen area. Swelling and pain were associated with peripheral joints, commonly bilateral, associated frequently with generalized bodyache or myalgia. Other less frequent clinical findings were headache, nausea, throat pain, muscle cramps, poor appetite, gastritis and dry cough. 8 patients had history of taking NSAIDS before admission.

In all the 92 patients' supportive and symptomatic treatment was administered. Out of 92 patients, 76 of them were administered with either oral or intravenous antibiotics (ceftriaxone, Doxycycline, Augmentin or Levofloxacin), 1 on Tamiflu and 3 on
Antimalarials therapy (inj. Artesunate+ sulfadoxine and pyrimethamine). The fever in the confirmed cases subsided on symptomatic treatment after few days. There were no deaths reported in our study.

Since its first association with an outbreak in Tanganyika in the 1950s, Chikungunya virus had mostly been occurring sporadically in parts of Africa and Asia. The first major outbreak which was documented was in 2004 which spread in the next 4 years from Africa to parts of India and Islands in the Indian Ocean to South East Asia. During that time many countries across Europe and North America reported cases from travelers. (Erin Staples et al., 2009; Taubitz et al., 2007; Panning et al., 2008).

Outbreaks due to Chikungunya virus occur episodically in the Indian subcontinent. Increased contact between the human population and vector due to various factors in both rural and urban places such human displacement to seasonal monsoon failures, deforestation, disorganized urban planning and waste management have all led to increase in vector related arboviral and parasitic infections in the recent years (Mohan, 2006).

Two vectors Aedes aegypti and A.albopictus share the same epidemiological niches as the endemic zones of Dengue, Japanese encephalitis malaria Chikungunya and inrecent years the Zika virus. Co-infections and simultaneous outbreaks of these infections can be explained due to bite of the common vector the female Aedes mosquito. (Erin Staples et al., 2009; Ratsitorahina et al., 2008; Moulin et al., 2016).

Dengue fever is characterized by flu-like symptoms accompanied with headache, rash, body-ache and characteristically low platelet count. Chikungunya presents always with 
high grade fever, severe bodyache and peripheral arthralgia. Complications of Dengue infections such as encephalitis, hemorrhagic symptoms, severe hematological changes and fatal outcomes are rarely associated with Chikungunya virus. Chikungunya infection however results in prolonged and slow recovery from the polyarthralgias, often persisting for months (Chattopadhyay et al., 2016; Borgherini et al., 2008).

The age group between 40-49 years showed minimally higher preponderance $(38.8 \%)$ as compared to both 20-29 age group and 50$59(27.7 \%)$. In the study, both the sexes were equally affected. This was in agreement with other studies (Chattopadhyay et al., 2016). The study population being small, it is difficult to conclude that age can affect the susceptibility to this infection. In a predominantly agricultural area, vector borne diseases such as Rickettsial infections or Chikungunya can be considered as occupational risks. The panel of tests for the emergency department should contain rapid tests specific for the diseases endemically or sporadically present in that area. The Laboratory should try to get tests repeated after appropriate interval in cases of high suspicion if the tests are negative.

In our study as described in the Table 2, the similarities in the clinical presentation between Chikungunya and Dengue were comparable in most instances (Erin Staples et $a l .$, 2009). While the inclusive criteria of the study were the presence of fever and body ache/joint pains, few presentations such as the polyarthragia, bleeding dyscrasias and hematological changes were the only marked delineating characteristics to clinically differentiate them. In both the infections, patients of various age groups are affected and any underlying cause as Diabetes mellitus, COPD or pregnancy can seriously affect the outcome for the patient. Many studies have noted the difficulty in clinically diagnosing the vector-borne diseases without the laboratory support.

Laboratory diagnosis of most of the arboviral infections is either ELISA or serological test based on antigen or specific antibody. In acute phase of the febrile illness, most patients may present with similar clinical symptoms and to alleviate, the clinician has to depend on rapid tests. The rapid POC tests are relatively cheaper, widely available, easy to perform, produce faster results but are subjective and can only be used as screening tests due to low specificity (Stacey et al., 2015; Prat et al., 2014). These rapid tests are critical in differentiating Chikungunya from other arboviral infections to institute the correct emergency procedures.

After the onset of symptoms, $\operatorname{IgM}$ and $\operatorname{IgG}$ antibodies to Chikungunya become detectable after $3 \mathrm{rd}$ and $6^{\text {th }}$ day of respectively. IgM antibody levels peak around 3 to 5 weeks and may persist for 3 months (Prat et al., 2014; Labadie et al., 2010). These tests show variable sensitivity and without a more advanced test kit like ELISA being easily available, standardizing the IgM kits in the field becomes difficult. The sensitivity may vary with the progress of the disease. According to one study the sensitivity of the immune-chromatographic tests was found to be $22 \%$ in the first week (Rianthavorn et al., 2010). The rapid POC tests are qualitative tests and may not reflect the severity or prognosis of the disease. Therefore the criteria to check for 4 fold rise in titres cannot be fulfilled. A negative result cannot preclude the presence of infection as the antibodies appear after 3 days and are not sensitive to low titres. Other factors such as heterophile antibodies or rheumatoid factors can confuse the result. 


\begin{tabular}{|l|l|l|l|l|}
\hline \multicolumn{5}{|l|}{ Table 1 Age and sex distribution for Chikungunya cases } \\
\hline $\begin{array}{l}\text { Range in } \\
\text { years }\end{array}$ & male & female & $\begin{array}{l}\text { Positivity } \\
\text { rate }\end{array}$ & Total \\
\hline$<20$ & 1 & 2 & 0 & 3 \\
\hline $20-29$ & 13 & 15 & $5(17.8)$ & 28 \\
\hline $30-39$ & 8 & 8 & $1(6.25)$ & 16 \\
\hline $40-49$ & 10 & 7 & $7(41.1)$ & 17 \\
\hline $50-59$ & 10 & 6 & $5(31.2)$ & 16 \\
\hline $60-69$ & 4 & 3 & $1(14.2)$ & 7 \\
\hline$>70$ & 3 & 2 & 0 & 5 \\
\hline Total & 49 & 43 & 0 & 92 \\
\hline
\end{tabular}

\begin{tabular}{|c|c|c|c|}
\hline $\begin{array}{l}\text { Clinical and lab } \\
\text { parameters } n=92\end{array}$ & $\begin{array}{l}\text { Chikungunya IgM } \\
\text { positive -18 (\%) }\end{array}$ & $\begin{array}{l}\text { Dengue IgM } \\
\text { positive- } \\
15(\%)\end{array}$ & $\begin{array}{l}\text { Other clinical conditions } \\
\text { Chik-IgM negative, Dengue } \\
\text { IgM negative- } 69(\%)\end{array}$ \\
\hline High grade fever & $18(100)$ & $10(66.6)$ & $32(46.3)$ \\
\hline Polyarthralgia & $15(83.3)$ & $1(6.6)$ & $4(5.7)$ \\
\hline Rash & $8(44.4)$ & $7(46.6)$ & $6(8.6)$ \\
\hline Muscle cramps & $5(27.7)$ & $2(13.3)$ & $8(11.5)$ \\
\hline Poor appetite & $11(61.1)$ & $10(66.6)$ & $54(78.2)$ \\
\hline Bodyache/ myalgia & $14(77.7)$ & $12(80)$ & $56(81.1)$ \\
\hline $\begin{array}{l}\text { Headache with/without } \\
\text { nausea }\end{array}$ & $3(10.6)$ & $12(80)$ & $27(39.1)$ \\
\hline Leucopenia & $10(55.5)$ & $2(13.3)$ & $11(15.9)$ \\
\hline $\begin{array}{l}\text { Thrombocytopenia < } \\
100000 \text { cells } / \mathrm{ml}\end{array}$ & $3(10.6)$ & $14(93.3)$ & $13(18.8)$ \\
\hline Vomiting & $1(5.5)$ & $10(66.6)$ & $22(31.8)$ \\
\hline Hemorrhaghic outcomes & - & $4(26.6)$ & - \\
\hline
\end{tabular}

A positive result may not distinguish between acute and recent past ( $<3$ months) infection. (Blacksell et al., 2011; Rianthavorn et al., 2010; Burdino et al., 2016).

Cross-reactivity with other arboviral infections as Sindbis and Semliki viruses may produce false positive results (Yiu-Wing Kam et al., 2015). As compared to other tests which require specialized equipment and available space, a POC rapid test can help in early diagnosis and reduce risk of morbidity in the infected patients. While viral cultures and molecular assays can clinch the diagnosis, in the field or in smaller hospital, a rapid POC kits are more practical and economically feasible.

In conclusion, in high prevalence areas, the rapid IgM based tests may perform poorly as a screening test and need to be supported with immunoassays for confirmation. With the 
improvement in medical tourism, expanding and changing epidemiology of the vectorborne diseases, it becomes very essential to differentiate these pathogens using rapid bedside efficient and easy to perform serological tests.

\section{Acknowledgment}

The author is thankful to Ms. Kirthi Mary for her help in processing the samples and maintaining the records.

\section{References}

Blacksell, S.D., Tanganuchitcharnchai, A., Jarman, R.G., Gibbons, R.V., Paris, D.H., Bailey, M.S., Day, N.P., Premaratna, R., Lalloo, D.G., de Silva, H.J. 2011. Poor diagnostic accuracy of commercial antibody-based assays for the diagnosis of acute chikungunya infection. Clin. Vaccine Immunol., 18: 1773-1775.

Borgherini, G., Poubeau, P., Jossaume, A., Gouix, A., Cotte, L., Michault, A., Arvin-Berod, C., Paganin, F. 2008. Persistent arthralgia associated with chikungunya virus: a study of 88 adult patients on reunion Island. Clin. Infect. Dis., 47(4): 469-75.

Briolant, S., Garin, D., Scaramizzino, N., et al. 2004. In vitro inhibition of chikungunya and Semliki forest viruses replication by antiviral compounds: synergistic effect of interferon-alpha and ribavirin combination. Antiviral Res., 61: 111-117.

Burdino, E., Calleri, G., Caramello, P., Ghisetti, V. 2016. Unmet Needs for a Rapid Diagnosis of Chikungunya Virus Infection. Emerg. Infect. Dis., 22(10): 1837-1839.

Centers for Disease Control and Prevention. 2015. National Center for Emerging and Zoonotic Infectious Diseases
(NCEZID), Division of Vector-Borne Diseases (DVBD). www.cdc.gov/chikungunya/geo/index.h tml

Chattopadhyay, S., Mukherjee, R., Nandi, A., Bhattacharya, N. 2016. Chikungunya virus infection in West Bengal, India. Indian J. Med. Microbiol., 34: 213-5.

Dev, V., Khound, K., Tewari, G.G. 2014. Dengue vectors in urban and suburban Assam, India: entomological observations. WHO South-East Asia J. Public Health, 3(1): 51-59.

Directorate of national vector borne disease programme (NVBDCP), New Delhi. 2016. National guide for clinical management for Chikungunya.

Erin Staples, J., Robert, F., Breiman, Ann, M. Powers. 2009. Chikungunya Fever: An Epidemiological Review of a ReEmerging Infectious Disease. Clin. Infect. Dis., 49: 942-8.

Labadie, K., Larcher, T., Joubert, C., Mannioui, A., Delache, B., et al. 2010. Chikungunya disease in nonhuman primates involves long-term viral persistence in macrophages. J. Clin. Invest., 120: 894-906.

Mohan, A. 2006. Chikungunya fever: clinical manifestations \& management. Indian J. Med. Res., 124(5): 471-4.

Moulin, E., Selby, K., Cherpillod, P., Kaiser, L., Boillat-Blanco, N. 2016 Simultaneous outbreaks of dengue, chikungunya and Zika virus infections: diagnosis challenge in a returning traveller with nonspecific febrile illness. New Microbes New Infect., 11: 6-7.

Murray, C., Rosenfeld, L.C., Lim, S.S., et al. 2012. Global malaria mortality between 1980and 2010: a systematic analysis. Lancet, 379: 413-431.

Panning, M., Grywna, K., van Esbroeck, M., Emmerich, P., Drosten, C. 2008. Chikungunya fever in travelers returning to Europe from the Indian 
Ocean region, 2006. Emerg. Infect. Dis., 14: 416-22.

Prat, C.M., Flusin, O., Panella, A., Tenebray, B., Lanciotti, R., Leparc-Goffart, I., et al. 2014. Evaluation of Commercially Available Serologic Diagnostic Tests for Chikungunya Virus. Emerg. Infect. Dis., 20(12): 2129-2132. https://dx.doi.org/10.3201/eid2012.1412 69

Ratsitorahina, M., Harisoa, J., Ratovonjato, J., et al. 2008. Outbreak of dengue and chikungunya fevers, Toamasina, Madagascar, Emerg. Infect. Dis., 14: 1135-7.

Rianthavorn, P., Wuttirattanakowit, N., Prianantathavorn, K., Limpaphayom, N., Theamboonlers, A., Poovorawan, Y. 2010. Evaluation of a rapid assay for detection of IgM antibodies to chikungunya. Southeast Asian J. Trop. Med. Public Health, 41: 92-96.
Stacey, K., Mardekian and Amity, L. Roberts 2015. Diagnostic Options and Challenges for Dengue and Chikungunya Viruses. BioMed. Res. Int., Volume 2015 Article ID 834371, 8 pages.

http://dx.doi.org/10.1155/2015/834371

Taubitz, W., Cramer, J.P., Kapaun, A., et al. 2007. Chikungunya fever in travelers: clinical presentation and course. Clin. Infect. Dis., 45: e1-4.

Yiu-Wing Kam, Kwoon-Yong Pok, Kai ErEng, Li-Kiang Tan, Simrandeep Kaur et al. 2015. Sero-Prevalence and CrossReactivity of Chikungunya Virus Specific Anti-E2EP3 Antibodies in Arbovirus-Infected Patients. PLoS Negl. Trop. Dis., 9(1): e3445.

WHO. 2009. Dengue Guidelines for Diagnosis, Treatment, Prevention and Control, WHO, Geneva, Switzerland.

\section{How to cite this article:}

Swapna Kurup Rajgopal. 2017. Diagnosis of Chikungunya by a Rapid Immunochromatographic Methodin a Tertiary Care Setting. Int.J.Curr.Microbiol.App.Sci. 6(3): 818-824. doi: https://doi.org/10.20546/ijcmas.2017.603.096 